\title{
DA PSICANÁLISE AO ENSINO DE CIÊNCIAS: $O$ "DESEJO DO DOCENTE" E O "PROFESSOR COMO UM LUGAR”
}

\author{
From psychoanalysis to science teaching: \\ the "teacher's desire" and the "teacher as a place"
}

Sergio de Mello Arruda ${ }^{1}$. Marinez Meneghello Passos ${ }^{2}$

Resumo: Apresentamos, neste trabalho, reflexões produzidas no contexto de um grupo de pesquisa, deflagradas a partir da seguinte questão: seria possível fundamentar a Formação de Professores como uma metáfora a Lacan? Como resposta positiva a esta questão, discutimos aqui dois exemplos: (i) inicialmente, apresentaremos a ideia de "desejo do docente", um conceito que poderia operar no campo da Formação de Professores de maneira semelhante ao desejo do analista no campo da Psicanálise; (ii) em seguida, a metáfora do "professor como um lugar". A apresentação de cada um dos pontos é seguida de extratos de diálogos entre pesquisadores, que ocorreram durante um encontro de pesquisa. Como foi possível mostrar, por meio da apresentação dos diálogos, a proposta de metaforizar frases da psicanálise de orientação lacaniana produziu discussões ricas em ideias e questões originais, dentro do enfoque geral de evidenciar suas implicações para o ensino de ciências e para a educação.

Palavras-chave: Formação de professores. Psicanálise. Ensino de ciências. Lacan, Jacques.

\begin{abstract}
We began this work with the following theoretical question: is it possible understand the Teacher Education field as a metaphor from Lacan's ideas? As a positive answer to this question, we discuss here two examples: (i) first, we present the idea of "teacher desire", a concept that may operate in teacher education in the same way as the analyst's desire operates in psychoanalysis; (ii) then, we present the "teacher as a place" metaphor. The presentation of each of the perspectives is followed by excerpts from conversations between researchers, which occurred in a research group. By presenting the dialogues, it was possible to show, that the metaphorized Lacanian phrases have produced rich discussions and original ideas within the general approach to highlight the implications of psychoanalysis for science teaching and education.
\end{abstract}

Keywords: Teachers education. Psychoanalysis. Science education. Lacan, Jacques.

\footnotetext{
${ }^{1}$ Departamento de Física, Universidade Estadual de Londrina (UEL). Rodovia Celso Garcia Cid (PR 445), Km 380, Campus Universitário. Cx. Postal 6001. Londrina, PR, Brasil. 86.051-980. Com apoio do CNPq. sergioarruda@sercomtel.com.br

${ }^{2}$ Departamento de Matemática, UEL. Londrina, PR, Brasil.
} 
Arruda, S. M.; Passos, M. M.

\section{Introdução}

Este trabalho tem como objetivo apresentar alguns resultados de investigações desenvolvidas em um grupo de pesquisa da Universidade Estadual de Londrina ${ }^{3}$, que partilha do pressuposto de que a Psicanálise pode contribuir significativamente para a pesquisa na área de Ensino de Ciências e Matemática. As reflexões produzidas, no contexto deste grupo, a partir da observação do comportamento de alunos e professores em situações de formação inicial e formação continuada realizadas nos últimos dez anos, geraram uma demanda teórica por uma diretriz geral que pudesse orientar nossa pesquisa, a qual poderia ser assim enunciada: "Seria possível falar sobre a educação de forma semelhante a que Lacan falava sobre a Psicanálise? Mais especificamente: seria possível fundamentar a Formação de Professores como uma espécie de metáfora a Lacan?”

O presente trabalho foi elaborado a partir de parte dos slides apresentados e discutidos no II Encontro do projeto Formação de professores de ciências: uma articulação entre pesquisas, realizado em junho de 2008 na cidade de São Paulo. Serão abordados dois pontos neste trabalho: (i) inicialmente, apresentaremos a ideia de desejo do docente, um conceito que poderia operar no campo da Formação de Professores de maneira semelhante ao desejo do analista no campo da Psicanálise; (ii) em seguida, será apresentada a metáfora do professor como um lugar. A apresentação de cada um dos pontos é seguida de extratos dos diálogos que ocorreram durante o II Encontro, os quais foram registrados em documentos escritos, denominados memórias ${ }^{4}$, no caso, as Memórias 09 e 10, registradas em junho de 2008 e disponibilizadas, posteriormente, ao grupo. Os diálogos foram parcialmente editados, para torná-los mais inteligíveis ao leitor.

Ao trazer esses dois exemplos para o grupo, procurando metaforizar frases de Lacan e da Psicanálise de orientação lacaniana, conforme apresentado nas seções seguintes deste texto, nossa intenção foi contribuir para a elaboração de novos sentidos para as pesquisas no Ensino de Ciências e Formação de Professores (FP).

\section{O desejo do docente}

Podemos observar que Lacan fala com bastante frequência, nos Seminários, sobre o que ele denomina de seu "ensino" e sobre a "transmissão" da Psicanálise; fala sobre a "formação" do analista e sobre o que fundamentaria sua prática. Por exemplo, no Seminário 11, Lacan (1998, p. 218) diz: "O fim do meu ensino tem sido, e permanece, o de formar analistas". Frases como esta nos levaram a pensar na possibilidade de operar uma espécie de espelhamento com relação ao pensamento lacaniano, de tal forma a traduzir suas frases para o contexto da Formação de Professores (FP), uma operação que poderia ser considerada uma metáfora.

A metáfora consiste basicamente "em dar a uma coisa um nome que pertence a outra” (ARISTÓTELES apud TURBAYNE, 1982, p. 23), produzindo-se, com isso, uma trans-

${ }^{3}$ Grupo Educação em Ciências e Matemática (EDUCIM), criado em 2002.

${ }^{4}$ Mais detalhes sobre as memórias podem ser encontrados em Passos et al. (2008). 
ferência de significado ou uma associação de ideias com base na analogia. Exemplos de metáforas: o homem é um lobo, a vida é um moinho, o átomo é um sistema solar, a luz é uma onda. Nesse sentido, a metáfora é um caso de tropo, ou seja, "do emprego de uma palavra ou frase em um sentido diferente do que lhe é próprio" (TURBAYNE, 1982, p. 23). Para Black (1966, p. 47, p. 49), a metáfora exerce uma importante função na ampliação do conhecimento: ela não só formularia ou explicitaria uma relação conhecida entre dois campos semânticos diferentes, mas poderia criar semelhanças estabelecendo novas conexões entre eles. O papel central da metáfora na aquisição do conhecimento novo é também defendido por Petrie e Oshlag (1993), para quem as metáforas, modelos e analogias podem providenciar uma ponte racional entre aquilo que se conhece e o radicalmente desconhecido 5 .

Mencionamos acima a frase de Lacan (1998, p. 218): “O fim do meu ensino tem sido, e permanece, o de formar analistas". Entretanto, segundo Lacan, na comunidade psicanalítica, os princípios ou os critérios para definir um analista não passam de um cerimonial, de uma "simulação", pois não há, para o analista, nada em que ele possa se fundamentar "para exercer sua função". $\mathrm{Na}$ análise, no entanto, tudo funciona em função da confiança depositada pelo paciente no analista. Mas, “o que significa então essa confiança? Em torno de que ela gira?”, pergunta Lacan (1998, p. 218), acrescentando que, embora essa questão possa ser ignorada pelo paciente, não pode ser pelo psicanalista:

I A formação do psicanalista exige que ele saiba, no processo que conduz seu paciente, em torno do que o movimento gira. Esse pontopivô é o que eu designo pelo nome de desejo do psicanalista. (LACAN, 1998, p. 218)

Em outra passagem, no início do Seminário 11, diz Lacan:

II O desejo do analista, em cada caso, não pode de modo algum ser deixado fora de nossa questão, pela razão de que o problema da formação do analista o coloca. E a análise didática não pode servir para outra coisa senão para levá-lo a esse ponto que designo em minha álgebra como o desejo do analista. (LACAN, 1998, p. 17)

Se o desejo do analista, em consideração à formação do mesmo, é um ponto-pivô na Psicanálise, no sentido de fundamentar a ação do psicanalista, não poderíamos pensar em um ponto similar na Formação de Professores? Algo como o desejo do docente ou desejo do professor? Para ver como ficaria esse conceito na rede conceitual da área de FP, basta transpor as citações I e II para este campo. Teríamos:

I(t) A formação do docente exige que ele saiba, no processo que conduz seu aluno, em torno do que o movimento gira. Esse ponto-pivô é o que eu designo pelo nome de desejo do docente. (transposto a partir de I)

\footnotetext{
${ }^{5}$ Parágrafo extraído, com adaptações, de Arruda (1993).
} 
Arruda, S. M.; Passos, M. M.

II(t) O desejo do docente, em cada caso, não pode de modo algum ser deixado fora de nossa questão, pela razão de que o problema da formação do docente o coloca. E a docência didática (?) não pode servir para outra coisa senão para levá-lo a esse ponto que designo em minha álgebra como o desejo do docente. (transposto a partir de II)

As substituições nas duas frases acima foram realizadas segundo o Quadro 1:

Quadro 1. Equivalência entre termos da Psicanálise e da Formação de Professores

\begin{tabular}{|c|c|}
\hline Analista & Docente $^{6}$ \\
\hline Analisando (paciente) & Discente (aluno) \\
\hline Análise & Docência \\
\hline Formação do analista & Formação do docente \\
\hline Desejo do analista & Desejo do docente \\
\hline Análise didática & Docência didática (?) \\
\hline
\end{tabular}

Fonte: Os autores

Com relação à proposta de transpor Lacan para a FP, as discussões ocorridas no II Encontro em São Paulo, na forma de comentários e questões, focalizaram alguns termos específicos da Psicanálise, bem como a plausibilidade da aplicação da ideia. Dúvidas foram expressas, por exemplo, a respeito do que seria a análise didática:

Jesuína: $O$ que é análise didática?

Villani: $A$ análise didática é a que o analista fazpara se tornar analista.

De fato, esta análise é definida como a "psicanálise pessoal, exigida de todo candidato a psicanalista" (CHEMAMA, 1995, p. 47). A análise didática está muitas vezes associada à supervisão (ou controle), ou seja, à prática obrigatória, sistematizada pela Associação Internacional de Psicanálise (IPA), em 1925, e que designava

[...] uma psicanálise conduzida com um paciente por um psicanalista que, por sua vez, encontra-se em análise didática e que concorda em ser supervisionado ou controlado, isto é, a prestar contas dessa psica-

\footnotetext{
${ }^{6}$ Estamos preferindo a palavra docente a professor, em função das diferenças entre as raízes latinas de ambas as palavras. No caso da primeira é doc(t)-, antepositivo de docèo, es, docùi, doctum, docére, 'fazer aprender, ensinar', do qual derivam, além de docente, dócil, doutrina, documento, doutor etc. No caso da segunda, é profess-, antepositivo de professio, ónis, 'declaração, manifestação', do qual derivam, além de professor, professar, profissão etc. (HOUAISS, 2001). Por isso, uma das acepções de professor é: aquele que professa uma crença, uma religião; enquanto que a de docente é: referente ao ensino ou àquele que ensina. Apenas no caso de Formação de Professores estamos mantendo a terminologia ao longo do texto por razões históricas.
} 
Da psicanálise ao ensino de Ciências: ...

nálise a outro psicanalista (o supervisor). (ROUDINESCO; PLON, 1998, p. 746)

Ana Raddi: De fato, a análise dita "didática" integra a formação psicanalítica, em organizações ligadas à IPA, mas sua especificidade tem sido objeto de controvérsias, mesmo dentro desta instituição. De fato, toda análise é "formadora", bem como deve colocar em jogo o desejo, qualquer que seja ele (inclusive o de se tornar psicanalista); daí a problematizaçãa da análise didática, com o agravante dela, no limite, violar os pressupostos do método psicanalítico: liberdade de percurso (a didática teria a finalidade de formação, portanto, função instrumental) e suspensão da censura (a didática, em algumas instituições, forneceria elementos à avaliação do candidato a analista). Alguns títulos de artigos, referentes a esta polêmica, aliás, ainda em curso, falam de per si: Meyer, Luiz "A análise didática deve ser mantida?" (2007) e "Subservient analysis" (2003); Laplanche, J. "A didática: uma análise encomendada" (1998).

O Quadro 1 evidencia pontos interessantes. Primeiro fica evidente a utilização da metáfora do docente (professor) como um analista e, consequentemente, a do analisando como discente (aluno), já proposta em Villani (1999). Mas a ideia de operar uma tradução da Psicanálise para a Formação de Professores parece problematizar tais metáforas, inserindo-as em uma estrutura maior. Por exemplo, o que considerar como a contraparte na FP da análise didática?

Jesuína: Por qual palavra você substitui [a análise didática]?

Sergio: Eu não substitui a análise didática por outra palavra, porque não há uma equivalente no campo da formação de professores. Por isso deixei uma interrogação no slide.

Entretanto, como a análise didática é um tipo de supervisão da análise, a docência didática, contraparte da análise didática, poderia ser entendida como uma supervisão da docência, ou como um tipo de estágio supervisionado, mas que procurasse conduzir o futuro professor ao seu desejo, ou evidenciar o seu desejo docente. Mas será que há mesmo um desejo do docente? Ou, pelo menos, será que há um desejo antes do envolvimento com a profissão?

Villani: Qual é a falta que ser professor vai tampar? O que o satisfaz? O que vai satisfazer?

Beth: É a paixão pela profissão?

Denise: Há desejos também nos processos de formação do professor. Nas situações em que dialoga sobre sua formação, sobre a formação de professores, ela está relacionada à formação pessoal também. Seria como remetê-lo ao seu desejo, por meio de sua atuação profissional. Seria como questioná-lo sobre onde ele está.

Washington: Encontrar o desejo, será? Acho que esse desejo só aparece depois, somente no percurso. A minha experiência mostra que a formação consegue lidar com a racionalidade técnica da vontade mais objetiva, do interesse em ser professor, e que essa questão do desejo, no melhor dos casos, vai aparecer no caminho. Essa racionalidade de que eu falo é a instrumental. Não dá para discutir o desejo desse cara. Ele está ali por opção, ou não. Nem pensou sobre tudo isso. [...] Olhando meus alunos... a questão do desejo é interessante, mas não vejo isso neles, acho que eles não têm desejos. Acho que eles têm interesse. Eu queria que eles desejassem, mas não desejam. É só interesse em ser professor, em se formar. Nem pensaram muito sobre: por que estão ali? 
Arruda, S. M.; Passos, M. M.

Denise: O trabalho da Dora mostra outra resposta. Há um desejo de satisfaz̧er pais, familia... muitos outros dessa ordem, dar continuidade à história da família. [...] Há desejos também nos processos de formação do professor. Nas situaçoes em que dialoga sobre sua formação, sobre a formação de professores, ela está relacionada à formação pessoal também. Seria como remetê-lo ao seu desejo, por meio de sua atuação profissional. Seria como questioná-lo sobre onde ele está.

Dos dados de que dispomos no grupo de Londrina, parece-nos que, em alguns casos, o desejo de ser professor surge muito cedo, quando criança. Mas cabe dizer que, ao se atribuir a algumas pessoas um desejo docente enraizado já na infância, não implicaria, necessariamente, que tal desejo tenha de se realizar na vida adulta.

Sergio: Temos o exemplo de uma professora que entrevistamos que, quando criança, dava aula para o seu cachorro. Ao que parece, já queria ser professora, já tinha o desejo.

Anne: Acho que isso não é bem assim, as justificativas mudam de ano para ano sobre o que queriam, eles justificam de maneiras diferentes as mesmas escolhas. Isso nós já tivemos nos nossos dados, quando ouvimos os mesmos alunos em anos diferentes, para uma mesma escolha eles dão mais de uma explicação. Lembranças sobre dar aula - todos nós demos aula, mas nem todos fomos ser professores, os engenheiros também lembram que na infância deram aula. Tem sempre essa lembrança por aí, mesmo para aqueles que não são professores, acho que todos nós demos aula quando criança - fizemos o papel de ensinar alguém.

Passemos agora ao segundo ponto a ser abordado nesse trabalho: a metáfora do professor como um lugar.

\section{O professor como um lugar}

A ideia do professor como um lugar surgiu da leitura de frases do seminário $O$ lugar e o laç, Primeira Aula, de Jacques-Alain Miller (2001), o responsável pelo estabelecimento dos textos dos Seminários de Lacan.

Em certo momento, Miller (2001) se refere ao laço que une o analista e seu grupo de analisandos, ex-analisandos, analistas em formação etc., que formariam como que um conjunto coordenado - um "sistema", ou mesmo uma "estrutura"7. Todos estão presos pelo laço que os une ao analista, este sendo a parte "pregnante" do mesmo. Mas o analista está no laço e

\footnotetext{
7 “O posto, às vezes, é disputado. Enquanto que o lugar é muito mais pacífico, muitos se aproximam dele, e pode acontecer que estes muitos sejam coordenados. Eis o laço que acontece. Se esses muitos são coordenados, então há chances de que cada um tenha seu posto. Quando isto ocorre com êxito, isso é mesmo susceptível de se apresentar como um sistema, e mesmo como uma estrutura. É assim que o lugar, bem coordenado, permite distinguir uma multiplicidade de postos, e é aí que pode transformar o que Lacan chamou um discurso onde se articulem postos e elementos" (MILLER, 2001, Primeira Aula).

${ }^{8}$ Pregnante, pregnância vêm do adjetivo latino praegnas, que significa prenhe (animal) ou grávida (mulher) (HOUAISS, 2001).
} 
também além dele; o analista é "alguém" - um outro - como todos, mas é também, e principalmente, o lugar "que condiciona o laço". O lugar do analista é mais do que o lugar de alguém: primeiro, porque o lugar do analista não é um lugar qualquer, mas um lugar "fundamental" e, segundo, porque o analista não é um alguém qualquer, mas o sujeito suposto saber. Por isso, o analista é um lugar:

O resultado é esta espécie de lugar fundamental, e no qual Lacan colocou o acento e que se chama lugar de despejo. É nisto que o analista é um lugar - como se diz o lugar - e que nesse lugar se estabeleça um laço. [...] Isto quer dizer, por exemplo, que o analista na sua prática está em dois lugares. Ele está por um lado num laço, parte pregnante do laço, o analisando sendo a parte presa, e ao mesmo tempo ele é o lugar, e aí é muito difícil para ele fazer laço entre o laço e o lugar. Portanto, o psicanalista é alguém, mas é também o auditor. [...] da espécie assim chamada sujeito suposto saber. E é aqui o lugar que condiciona o laço. (MILLER 2001, grifo nosso)

Muito bem, se o analista é um lugar, como seria pensar no professor como um lugar? A ideia nos pareceu atraente, pois já havíamos percebido, dos dados de que dispúnhamos no nosso grupo de pesquisa, que a questão - O que é ser professor? - era, aparentemente, uma das questões implícitas que inquietavam o estudante da licenciatura no momento do estágio supervisionado.

Nas discussões do grupo, algumas questões surgiram, naturalmente, em relação a essa metáfora: qual a natureza desse lugar? Seria um lugar de despejo, como na frase de Miller? Que relações o lugar teria com o gozo e com o desejo? Qual a diferença entre lugar e posição? Se o professor é um lugar, será que é possível pensar no aluno como um lugar também?

Villani: $O$ analista pode ser considerado lugar de despejo. $O$ analisando despeja seus podres. O professor não é esse lugar, de despejo. Nem saberia ser. [O lugar do professor] não seria o lugar dos sonhos profissionais... do que o aluno sonba ou do que o professor sonba? O professor seria um instrumento seria o lugar onde se formam as esperanças. Pode-se mudar a escola se o professor pensar assim. Ele pode também repensar sua prática, a escola, o que ele quer. Temos dois pontos - que lugar é esse e como fazer que isso melhore o desempenho do professor.

Embora, em alguns momentos da discussão, a ênfase tenha sido colocada sobre o lugar como um lugar de despejo, não estávamos preocupados com adjetivar o lugar, mas de vê-lo enquanto elemento estruturante de um sistema. O lugar estaria além da pessoa do analista. Ou seja, se o professor operasse como um lugar, em uma estrutura semelhante à do analista, talvez isso pudesse ser um ponto de partida interessante para pensar a Formação de Professores.

Outra observação que podemos fazer é a de que a proposta do professor como um lugar produziu vários deslizamentos de sentido, um deles, da ênfase no lugar para a metáfora professor/analista, já conhecida pelo grupo:

Beth: O analista sustenta o cara para atravessar o fantasma. E o professor? 
Arruda, S. M.; Passos, M. M.

Villani: O analista está ali para fazer a passagem (o analisando assumir seu gozo). E o professor...? Na psicanálise, ao falar tudo o que lhe vem na cabeç, o analisando atualiza seu gozo e de alguma forma pode organizá-lo. Será que o aluno ao falar na escola consegue organizar seu conbecimento? "Quem sabe pergunta, quem responde aprende". Talvez isso seja o essencial para o professor: perguntar para que o aluno organize seu conbecimento.

Outro deslizamento de sentido, com desdobramentos interessantes, ocorreu entre as frases o professor como um lugar e o lugar do professor, nas quais, a princípio, a palavra lugar desempenharia funções diferentes. Em particular, podemos perguntar: de onde fala o professor? Ele fala de um lugar, ou de uma posição?

Sergio: Primeiro, de onde estamos falando? De onde falamos? Pode ser de vários lugares; podemos falar com base em vários referenciais. Isso nos remete a compreensões diferentes e a lugares diferentes.

Villani: Acho que devemos distinguir lugar de posição. Acho que você está tratando de posição e não de lugar, certo? Quando você fala de um determinado lugar, significa que você assumin totalmente as características do oficio. Quando você fala de uma posição, significa que você tomou emprestado, temporariamente, as características do oficio. Se boto a mão no fogo - se acho que vai resolver o meu problema de forma definitiva, então falo de um lugar. Pelo contrário, se acho que o referencial me empresta alguns conceitos importantes para o caso, então falo de uma posição. Tem que pensar: falamos de uma posição ou de um lugar? Acho que falar de uma posição permite um diálogo maior. Um problema que encontrei, algumas vezes, nas palestras de psicanalistas que falam de educação é que falam do lugar da psicanálise, ou seja, embutindo implicitamente as finalidades da Psicanálise (que é ajudar o analisando a lidar com seu gož fundamental) e não da educação científica (que é ajudar o aluno a lidar com o conbecimento cientifico). Algumas vezes é importante que o professor ajude um aluno particular, num momento particular, a lidar com seus problemas psíquicos, mas isso não é sua função essencial. Da mesma forma, algumas vezes o psicanalista atua da posição de educador, para superar um determinado impasse, mas isso é provisório.

Verónica: Creio que ai tem responsabilidade do professor. Não é só despejo. O lugar do professor não é só o do despejo, mas que também existe responsabilidade na tarefa, um gozo.

Denise: Eu pensei não o lugar, mas o desejo. Estamos falando do outro, mas nós também somos professores. Eu também tenho demandas. Há lugares diferentes - ou é um só lugar? Há vários lugares - dependendo do lugar, seria isso? Mas junto a esse lugar, aí vem o desejo... Nós também temos desejos... nós também temos demandas... não somente os professores ou alunos com quem trabalbamos. Temos que pensar nisso no nosso lugar, no nosso desejo e nas nossas demandas.

Alice: Quanto ao lugar - existem vários, para ele, o professor, assim como para nós. Não consigo olhar para o professor como estando em um lugar ou outro, acho que é um conjunto de desejos que são diferentes dependendo da forma como se olha para eles. Tenho receio de tentar localizar esse professor em um único lugar. Ele transita por vários, tem o lugar na aula, na direção, no sindicato.

Outra questão central diz respeito à essência deste lugar, ao gozo que o caracterizaria, em uma tentativa de diferenciar o professor, do analista e do pesquisador:

Villani: Qual a essência desse lugar? Como descobrir isso? Ai temos o que caracteriza mesmo o professor? Ele tem muitas funções, mas o lugar refere-se ao mais fundamental! O gozo do professor parece-me 
que está em questão. Como faz̧er isso - descobrir a essência desse lugar? Como descobrir o algo ao qual o professor fica amarrado? Se encontrarmos isso, se conseguirmos desvendar, vai ser uma contribuição importante. [...] Na frase de Miller (Jacques-Alain) - o analista é um lugar de despejo. Acho que isso quer dizer que o gozo do analista está em ser lata de lixo. O analista gosta do tenebroso, do confuso, do inominável - é com isso que ele goza. Da mesma forma o cirurgião gosta de sangue, gosta de cortar - o cirurgião gosta, senão não consegue ser um bom cirurgião. Qual é gozo do professor? Com o que ele goza? Cada um tem o seu gozo, quando este se aproxima ao gozo do professor tem chances de ser um bom professor. Será o palco? É esse o gozo do professor? Se o analista gosta do ambíguo, do inominável, daquilo que queremos jogar fora, por isso consegue ajudar o analisando a lidar com isso, do que o professor gosta mesmo? Pareceu-nos que ele gosta da ignorância, do preconceito, por isso consegue ajudar o aluno a superar seus limites. Um bom professor nunca fica escandalizado com o desconbecimento de seus alunos. Pelo contrário, quando encontra isso logo quer mexer, ajudar. É importante dizer que não vale a reciproca: se um cirurgião gosta de sangue, não necessariamente vai ser um bom cirurgião; pode se tornar serial killer. Assim como um psicanalista, ao invés de ajudar seus clientes pode explorá-los. E o professor pode aproveitar da ignorância de seus alunos para dominá-los e terrorizá-los.

Sergio: Ao que parece cada professor se amarra de um jeito. Em alguns dados a gente já viu que tem a questão de ocupar o palco; em outros casos parece que o reconbecimento do outro é o mais importante. [...] Vejamos, por exemplo, o orientador é um professor?

Jesuína: Não, são diferentes.

Villani: Eu acho que tem algo em comum e algo diferente. Ambos lidam com a ignorância, o pouco claro, o pouco convincente. Porém, o desafio do bom professor é superar a ignorância dos alunos levando-os na direção do conbecimento científico, ao passo que o desafio do pesquisador é superar a ignorância dele e de todos numa direção não definida, porém que respeita determinados vínculos. Entretanto, quando o professor não sabe como convencer seus alunos o seu desafio é semelhante ao do pesquisador. Em minha interpretação sobre o lugar como a característica essencial: o professor não precisaria ser sempre inovador, precisa saber lidar com a ignorância dos alunos para eles se encantarem com o conbecimento dele. Um bom professor é o que consegue levar a maioria dos alunos a se encantar com o conhecimento dele. Algumas vezes ele deve ser inovador, quando encontra impasses. Ele lida com o coletivo. Pelo contrário, o pesquisador lida com o individual, o conhecimento específico que ainda não foi construído. Para fazer isso não precisa sempre ser original, mas em algum momento precisa inventar.

Ainda sobre o lugar do professor, surge também a questão do lugar do aluno:

Denise: Os lugares que ocupamos são diferentes, e os que queremos também. O ponto em questão era apenas mostrar que ocupamos um lugar diferente do aluno. Então há a necessidade de dar espaço de gozo para o meu aluno, mesmo que ele queira se manter no tradicional, dar uma aula tradicional, mostrar que sabe o conteúdo. Tenho que possibilitar isso a ele, é o gozo dele. Fiz essa referência para mostrar que estamos em lugares diferentes, eu e meu aluno, e o lugar que eu quero para ele e o que eu ocupo, tem muita distância aí.

Esta é também uma questão interessante. O gozo do aluno, o lugar do aluno. O que seria o aluno como um lugar? Será que existe? E quando isso existe? Qual é o lugar do aluno no discurso do professor? Tem alunos que ocupam lugares na sala de aula, lugares que competem com o lugar do professor. Os lugares estão vinculados a discursos que capturam os 
Arruda, S. M.; Passos, M. M.

ouvintes. O professor fala a partir de um discurso, o aluno de outro. Mas como se dá a ocupação de um lugar? E o estagiário, será que ele tem condições de ocupar um lugar?

Ana Raddi: A questão não é ocupar o lugar que ele tinha pronto, aquele dado pelo aluno. Eu ocupo o lugar que você me dá, mas não do jeito que você me dá, pois quem o ocupa son eu, e de que jeito é que en o ocupo? Essa é a questão.

Alice: Temos que ocupar para desocupar, esse é o lugar do professor. Ocupa e depois desocupa, para questionar. Tem que desalienar. Você ocupa o lugar que o aluno te dá e depois sai dele.

Lizete: Enquanto estagiário, ele não tem o lugar... Ou é um lugar um pouco de mentira... Porque a formação mesmo só acontece no exercício da profissão. Parece-me que quem está na profissão, tem seu lugar, enquanto estagiário não é bem um lugar. O lugar do professor é daquele que está na profissão mesmo. Acho que não dá para separar o lugar do professor do exercício da profissão. Ou seja, acho que o professor só está nesse lugar de ser professor, apenas quando enfrenta a complexidade inteira, da relação com a instituição, da necessidade de chamar os pares para a reflexão conjunta, enfim, quando compra o pacote inteiro. Antes disso entra nesse papel de mentira. Só posso falar mesmo quando a complexidade está inteira. Na formação inicial, não; parece falso.

Esta última frase (Lizete) remete a um foco de interesse para nosso programa de pesquisa, que envolve a seguinte questão: "O que podemos enxergar na educação e na formação de professores quando olhamos para esses campos a partir das categorias lacanianas do imaginário, simbólico e real?”

Sergio: Sobre o lugar, temos duas maneiras de pensar esse lugar, temos que considerar o imaginário e o simbólico. O simbólico traz. regras. Quando digo que o professor é um lugar, do ponto de vista simbólico, estou dizendo que ele tem que dançar conforme a música que ali é tocada. Então dar aula em um lugar ou outro (Universidade on colégio), muda tudo. Nessa situação somos uma carta com uma quantidade de jogadas possivieis. A universidade é uma instituição - com amplitude onde se trabalha mais livre - com mais possibilidades de jogo (do que no colégio). Dai tem o imaginário - en e o outro - en desejo o desejo do outro (como dir. Hegel). Agora, o lugar imaginário é o eu numa relação com o outro. Acho que estamos fazendo uma mistura dessas duas coisas. O estagiário não ocupa plenamente o lugar simbólico do professor.

Dora: A palavra coloca, mas não dį tudo. Falar de imaginário, simbólico e real separadamente não dá, não existe. Estão sempre juntos imaginário-simbólico-real. A gente separa para entender: o imaginário traz uma relação, a do que ele queria, do mundo dos desejos, das pulsões que nos movem. O real acontece de fato, aquilo que fazemos no concreto, que está diante de nossos olhos. Já o simbólico - está relacionado com a função, é estrutura, o mundo da linguagem perpassada pela cultura, está relacionado com o que você carrega, suas estruturas, liames. Tem a ver com as leis, com os contratos.

Ana Raddi: Penso que o real seja diferente do que foi dito. Na Psicanálise, o real é da ordem do que escapa à simbolização.

$\mathrm{Na}$ literatura, encontramos que o imaginário está ligado primordialmente à relação entre o eu e o outro, à constituição do eu como um reflexo da imagem do outro e ao fenômeno da identificação; tem a ver com os sentimentos (de amor e ódio, principalmente) que se desenvolvem na relação intersubjetiva. O simbólico é o mundo das palavras, do significante, que preexiste a todos nós e que define fundamentalmente o que seria humano. E o real é o que não 
Da psicanálise ao ensino de Ciências: ...

pode ser atingido ou compreendido, sendo da ordem do impossível. $O$ real não pode ser totalmente simbolizado, na palavra ou na escrita (CHEMAMA, 1995).

\section{Considerações finais}

Como foi possível mostrar, por meio da apresentação dos diálogos, a proposta de metaforizar frases da psicanálise de orientação lacaniana produziu discussões ricas em ideias e questões originais, dentro do enfoque geral de evidenciar suas implicações para o ensino de ciências e para a educação. Certamente, há limitações em analogias como essa. Uma análise não é um ensino e um docente não é um analista. No entanto, que tipo de grade conceitual poderia ser construída no campo da formação de professores ou da educação, operando metaforicamente sobre frases de Lacan? Esse é o espírito que anima esse tipo de jogo. Seja como for, pensar em um conceito tal como o desejo docente, como o fundamento do "ser professor", pareceu-nos ser um caminho possível para o pesquisador produzir novos resultados na área, tanto do ponto de vista teórico como experimental. Nesse sentido, foi interessante encontrar, no Seminário 10, a seguinte colocação de Lacan, que parece inverter o sentido da metáfora:

Eu disse a mim mesmo que não seria um caminho ruim, para introduzir o desejo do analista, lembrar que existe uma questão do desejo do docente [...]. O fato de podermos formular a alguém a questão do desejo do docente é sinal, como diria o sr. La Palice, de que a questão existe. E também sinal de que existe um ensino. (LACAN, 2005, p. 190)

Quanto à metáfora do professor como um lugar (em uma estrutura), ela foi aplicada na interpretação de dados do estágio supervisionado de Física (ARRUDA; BACCON, 2007; BACCON, 2005), partindo do pressuposto de que a profissão professor é essencialmente relacional, onde o professor, o aluno e o saber em questão (o conteúdo) ocupam como que os vértices de um triângulo ${ }^{9}$, e a aprendizagem é um processo sensível às posições que professores e alunos mantêm em relação ao conteúdo. Entretanto, o aluno precisa acreditar que o professor sabe para que possa confiar a ele o seu aprendizado. Caso contrário poderá optar, dentre outras possibilidades, por: aprender sozinho, com ajuda de um livro, por exemplo; decorar para apenas ser aprovado, sem um aprendizado real, fingindo que aprende; ou mesmo por rejeitar, de fato, qualquer aprendizado. Em uma relação efetiva de ensino-aprendizado, o professor ocupa um lugar especial no imaginário do aluno, e, como um analista, opera do lugar do sujeito suposto saber. Ou seja, a assunção deste lugar pelo professor depende da confiança que o professor desperta no aluno ou de quanto o aluno percebe e aceita o saber do professor. É preciso que haja laço entre o professor, o aluno e o saber. De qualquer forma, restaram várias questões a serem futuramente investigadas: qual seria a natureza desse lugar? É um lugar em um discurso? Como ele é construído pelo professor ou por um estagiário? Como se dá sua sustentação?

\footnotetext{
${ }^{9}$ Figura utilizada por Chevallard (2005).
} 
Arruda, S. M.; Passos, M. M.

\section{Referências}

ARRUDA, Sergio de Mello. Metáforas na Física. Caderno Catarinense de Ensino de Física. v. 10, n. 1, p. 25-37, 1993.

ARRUDA, S. M.; BACCON, A. L. P. O professor como um lugar: uma metáfora para a compreensão da atividade docente. Ensaio: Pesquisa em Educação em Ciências, v. 9, n. 1, p. 1-20, 2007.

BACCON, A. L. P. O professor como um lugar: um modelo para análise da regência de classe. 2005. 166 F. Dissertação (Mestrado em Ensino de Ciências e Educação Matemática) - Universidade Estadual de Londrina, Londrina, 2005.

BLACK, M. Modelos y metaforas. Madrid: Editorial Tecnos, 1966.

CHEMAMA, R. (Org.). Dicionário de psicanálise. Porto Alegre: Artes Médicas, 1995.

CHEVALLARD, Y. La transposición didáctica: del saber sabio al saber enseñado. Buenos Aires: Aique Grupo, 2005.

HOUAISS, A.; VILLAR, M. S. Dicionário Houaiss da língua portuguesa. Rio de Janeiro: Objetiva, 2001.

LACAN, J. O seminário. Rio de Janeiro: Jorge Zahar, 2005. (Livro 10: A angústia).

O seminário. 2. ed. Rio de Janeiro: Jorge Zahar, 1998. (Livro 11: Os quatro conceitos fundamentais da psicanálise).

MILLER, J. A. Orientação lacaniana: “O Lugar e o Laço” (2000-2001), primeira sessão do Curso, 15 nov. 2000. Trad. Instituto de Psicanálise Lacaniana (IPLA), São Paulo. Tradução de: L'orientation lacanienne, "Le lieu et le lien" (2000-01), inédit. Enseignement prononcé dans le cadre du Département de Psychanalyse de Paris VIII. 2001.

PASSOS, M. M.; ARRUDA, S. M.; PRINS, S. A.; CARVALHO, M. A. Memórias: uma metodologia de coleta de dados dois exemplos de aplicação. Revista Brasileira de Pesquisa em Educação em Ciências, v. 8, n. 1, p. 1-21, 2008.

PETRIE, H. G.; OSHLAG, R. S. Metaphor and learning. In: ORTONY, A. (Org). Metaphor and tought. Cambridge: Cambridge University Press, 1993. p. 579-609.

ROUDINESCO, E.; PLON, M. Dicionário de psicanálise. Rio de Janeiro: Jorge Zahar, 1998.

TURBAYNE, C. M. El mito de la metafora. México: Fondo de Cultura Económica, 1982

VILLANI, A. O professor de ciências é como um analista? Ensaio: Pesquisa em Educação em Ciências, Belo Horizonte, v. 1, n. 1, p. 5-28, 1999.

Artigo recebido em 17/06/2011. Aceito em 01/01/2012. 